\title{
Decreased serum obestatin consequent upon TRIB3 Q84R polymorphism exacerbates carotid atherosclerosis in subjects with metabolic syndrome
}

\author{
Ai-dong Cui ${ }^{1,2^{*}}$, Ning-ning Gai ${ }^{1}$ Xiu-hua Zhang ${ }^{1}$, Ke-zhi Jia ${ }^{1}$, Yan-li Yang ${ }^{1}$ and Ze-jun Song ${ }^{1}$
}

\begin{abstract}
Background: Functional TRIB3 Q84R polymorphism has been associated with insulin resistance. Obestatin improving insulin resistance, exerts obscure effects on metabolic syndrome (MetS) and carotid atherosclerosis. Aims to investigate whether the prevalent TRIB3 Q84R polymorphism has profound implications for alterations of serum obestatin and what effect obestatin exerts on carotid atherosclerosis.

Methods: A total of 518 unrelated Chinese subjects consisted of control $(n=258)$ and MetS $(n=260)$ groups. Clinical and biochemical characteristics were collected. The level of serum obestatin was measured. Genotype the functional TRIB3 Q84R polymorphism. All subjects underwent ultrasonography to determine carotid intima-media thickness (IMT).

Results: Serum obestatin was significantly decreased in MetS as compared with the control group $(P=0.042)$. Among the MetS group participants possessing RR84 genotype had significantly lower levels of serum obestatin than those with QQ84 or QR84 genotypes $(P=0.008, P=0.043)$ with similar significant difference among the control group. Factorial analyses showed statistically significant interactions between MetS and RR84 genotype $(P=0.009$ for interaction for obestatin). On correlation analysis, obestatin correlated negatively with homeostasis model assessment insulin resistance $(r=-0.163, P=0.010)$ and IMT $(r=-0.256, P=0.011)$. On partial analyses, obestatin negatively correlated with $\operatorname{IMT}(r=-0.259, P=0.024)$ after controlling for the confounding factors.
\end{abstract}

Conclusion: MetS individuals with TRIB3 RR84 genotype demonstrated further decreased serum obestatin. Decreased serum obestatin might in part exacerbate insulin resistance and carotid atherosclerosis.

Keywords: Obestatin, TRIB3, Metabolic syndrome, Carotid atherosclerosis

\section{Introduction}

The existence of metabolic syndrome (MetS) implies a shift from a pathophysiology concept based on metabolic abnormalities resulting from an insulin-resistant state to an epidemiological construct based on abdominal obesity and crude correlates of the features of insulin resistance. Excessive circulating adipocytokines might provide pathways linking abdominal obesity to insulin resistance,

\footnotetext{
* Correspondence: doc260@163.com

'Yantai Municipal Laiyang Central Hospital, Yantai 265200, People's Republic of China

2Department of Cardiology, No 111, Changshan Road, Laiyang, Shandong, ${ }^{2}$ Department of Cardiology,
People's Republic of China
}

\section{Biomed Central}

which has led several groups to try to identify secreted products derived specifically from this depot. Obestatin [1], reducing food intake, body weight gain, gastric emptying, and jejunal motility, has been demonstrated to be involved in insulin resistance and metabolic dysfunctions. The functional profiles of obestatin reported in the past studies would suggest a regulator of adipocyte metabolism by promoting adipogenesis in an autocrine/paracrine manner $[2,3]$, which pointing to a putative role in the pathogenesis of metabolic syndrome. However, at present the pathophysiological role of obestatin in MetS remains unknown. 
Table 1 Demographic characteristics of the studied population

\begin{tabular}{|c|c|c|c|}
\hline Characteristics & $\frac{\text { Control group }}{(n=258)}$ & $\frac{\text { MetS group }}{(n=260)}$ & $P$ \\
\hline Sex (male/female) & $155 / 103$ & 159/101 & 0.802 \\
\hline Age (years) & $54 \pm 8$ & $55 \pm 9$ & 0.182 \\
\hline$W C(\mathrm{~cm})$ & $82.08 \pm 7.69$ & $97.42 \pm 9.44$ & $<0.001$ \\
\hline SBP $(\mathrm{mmHg})$ & $114.90 \pm 10.85$ & $151.29 \pm 22.82$ & $<0.001$ \\
\hline $\mathrm{DBP}(\mathrm{mmHg})$ & $75.03 \pm 7.34$ & $93.47 \pm 13.70$ & $<0.001$ \\
\hline TG (mmol/L) & $1.02 \pm 0.40$ & $2.32 \pm 1.30$ & $<0.001$ \\
\hline $\mathrm{HDL}-\mathrm{C}(\mathrm{mmol} / \mathrm{L})$ & $1.56 \pm 0.36$ & $1.22 \pm 0.29$ & $<0.001$ \\
\hline FBG (mmol/L) & $4.83 \pm 0.60$ & $6.61 \pm 2.48$ & $<0.001$ \\
\hline Insulin ( $\mu \mathrm{U} / \mathrm{mL})$ & $10.63 \pm 4.73$ & $20.78 \pm 11.20$ & $<0.001$ \\
\hline Log(Obestatin) & $109.65 \pm 14.79$ & $95.50 \pm 13.80$ & $<0.001$ \\
\hline
\end{tabular}

Data are means \pm SD for normally-distributed variables.

Abbreviations: MetS, metabolic syndrome; WC, Waist circumference; SBP, systolic blood pressure; DBP, diastolic blood pressure; TG, triglycerides; HDL-C, high-density lipoprotein cholesterol; FBG, fasting blood glucose.

Studies addressing the molecular mechanisms have revealed that obestatin regulates adipocyte function and protects against diet-induced insulin resistance and inflammation [3]. As previously reported, obestatin is decreased in obese subjects [4]. However, whether decreased obestatin ameliorates or deteriorates insulin resistance remains obscure. Furthermore, what effects obestatin exerts upon carotid atherosclerosis remains unknown.

TRIB3 (a mammalian tribbles homolog, also known as TRIB3/NIPK, gene ID 57761), has been reported by most studies [5,6], although not all studies [7], implicated in the regulation of insulin signal transduction by binding to and inhibiting Akt phosphorylation and to play a role in insulin resistance $[5,6]$. Furthermore, it has been demonstrated that the TRIB3 gene, especially the R84 variant, could help identify individuals at risk for insulin resistance and carotid atherosclerosis risk by determining carotid intima-media thickness (IMT) [8]. As mentioned above, obestatin might go down with MetS, the key culprit of which is insulin resistance. Therefore, obestatin might be involved in MetS. However, whether the prevalent TRIB3 missense Q84R polymorphism has profound implications for alterations of serum obestatin and what effect obestatin exerts remain to be established.

In the present study, we aimed to investigate the role of obestatin in MetS and carotid atherosclerosis under the background of TRIB3 Q84R polymorphism by casecontrol study.

\section{Materials and methods}

A total of 518 unrelated homogenous Chinese subjects between the ages of 30 and 77 years were recruited from the Yantai Municipal Laiyang Central Hospital of
Shandong: 260 subjects [ 159 men; mean age $55 \pm 9$ years] with MetS, defined according to the 2005 criteria of the International Diabetes Federation; 258 subjects (controls) [155 men; mean age $54 \pm 8$ years] without cardiovascular diseases or elevated fasting glucose (fasting plasma glucose $\geq 5.6 \mathrm{mmol} / \mathrm{L}$ ) and with waist circumference less than $90 \mathrm{~cm}$ for men and $80 \mathrm{~cm}$ for women, defining central obesity, conducted from September 20, 2008 to June 2, 2011. Written informed consent was obtained from all subjects before enrollment in the study, and procedures were approved by the ethics committees of Yantai Municipal Laiyang Central Hospital of Shandong and followed the Helsinki Declaration criteria.

Subjects were advised to refrain from strenuous physical activity, smoking, eating and drinking for at least $12 \mathrm{~h}$ before the screening visit. Screening included the completion of standardized questionnaires collecting personal information and the collection of data on age, sex, personal medical history, and history of coronary heart disease, hypertension, dyslipidemia, and diabetes. Systolic blood pressure (SBP) and diastolic blood pressure (DBP) were measured twice in the right arm then averaged for subjects who had been resting for at least $10 \mathrm{~min}$ in a comfortable position. Waist circumference was measured at the midpoint between the iliac crest and the lower rib margin and hip circumference around the maximum circumference of the buttocks posteriorly and the symphysis pubis anteriorly.

\section{Laboratory measurements}

After blood samples were taken, plasma preserved with EDTA and serum were separated immediately by centrifugation at $2500 \mathrm{~g}$ for $10 \mathrm{~min}$. Glucose measurements involved the glucose oxidase method. Total cholesterol and total triglyceride levels were determined by enzymatic methods. HDL-C was measured in the supernatant after precipitation of apo B-containing lipoproteins with use of phosphotungstic acid and magnesium chloride. LDL-C level was calculated by use of the Friedewald formula. LDL-C was not calculated for individuals with triglyceride level $>4.5 \mathrm{mmol} / \mathrm{L}$. Serum concentration of insulin was determined by use of a radioimmunometric assay kit (Dongya Ltd, Beijing). Intra- and interassay coefficients of variation for insulin were $10 \%$ and $15 \%$, respectively; no cross-reactivity was observed between insulin and proinsulin. Insulin resistance was assessed from glucose and insulin concentrations by the use of

Table 2 Genotype and allele frequency of TRIB3 Q84R polymorphism in subjects with and without MetS

\begin{tabular}{lccccc}
\hline & QQ84 & QR84 & RR84 & Q84 & R84 \\
\hline Control group & 168 & 70 & 20 & 406 & 110 \\
MetS group & 155 & 79 & 26 & 389 & 131
\end{tabular}

Abbreviations: MetS, metabolic syndrome. 
Table 3 Comparison of levels of serum obestatin by TRIB3 Q84R genotype

\begin{tabular}{lcccc}
\hline & QQ84 & QR84 & RR84 & P for ANOVA \\
\hline $\begin{array}{l}\text { Control group } \\
(n=258)\end{array}$ & $151.36 \pm 11.75$ & $102.33 \pm 14.45^{* *}$ & $95.50 \pm 17.39^{* *}+$ & \\
$\begin{array}{l}\text { MetS group } \\
(n=260)\end{array}$ & $112.20 \pm 14.79$ & $100.01 \pm 16.98^{* *}$ & $70.79 \pm 19.50^{* *}+$ & $<001$ \\
\end{tabular}

Data are means \pm SD. ${ }^{* *} P<0.01$ vs QQ84 genotype, $+P<0.05$ vs QR84 genotype. Abbreviations are as in Table 1.

the homeostasis model assessment (HOMA) equation, which equals to fasting blood glucose multiplied by fasting insulin then divided by 22.5 [9]. Details about the anthropometric and biochemical parameters refer to Table 1 .

\section{Serum obestatin assay}

Serum obestatin was measured by a commercially available RIA kit (Phoenix Pharmaceuticals Inc., Mountain View, CA, USA) following the manufacturer's instruction. Samples were measured in duplicate in a single experiment. The intra- and interassay coefficients of variance of this kit are $<5 \%$ and $<14 \%$, respectively.

\section{Genotyping}

Genomic DNA was prepared from blood leukocytes by established methods. Genotyping of the TRIB3 R84 variant involved the RFLP-PCR method with the primers 5'- GGC CAC CAA GCA GTC TCAC - $3^{\prime}$ (forward) and $5^{\prime}$ - CGC CCA TGA TCC CTA AGT TC -3' (reverse). PCR conditions and protocols were as described by Prudente et al. [10]. Screening was performed by adding 1 unit of MspI restriction enzyme (Takara Biotechnology(Dalian) Co.,Ltd) into $15 \mu \mathrm{L}$ of PCR product. After 2-h incubation at $37^{\circ} \mathrm{C}$, products were loaded onto $1.5 \%$ agarose gel and visualized by staining with ethidium bromide. For genotyping, positive and negative controls (known sequences after sequencing) were used, and the rate of genotyping success for the SNP was $>99 \%$. (Additional file 1: Figure S1).

\section{Echocardiography}

All subjects underwent echocardiographic examination with a commercially available ultrasound machine (Vivid 7 dimension; General Electric Medical Systems, Horten, Norway) equipped with a $2.5 \mathrm{MHz}$ variable-frequency scanner as reported [8].

\section{Statistical analysis}

The Kolmogorov-Smirnov test was used to test for normal distribution. Normally distributed data are presented as means $\pm \mathrm{SD}$, and non-normally distributed data are presented as medians (quartile range). Non-normally distributed variables were given a log-transformation if necessary. Continuous variables were compared between groups by unpaired Student's $t$ test or Mann-Whitney $U$ test and among groups by one-way ANOVA with posthoc LSD $t$ test when appropriate. The chi-square test was used to analyze the associations between categorical variables and for Hardy-Weinberg equilibrium. The correlation between 2 variables was assessed by Pearson or Spearman correlation coefficient analysis. After controlling for covariates, bivariate correlations underwent partial correlation analysis. Next, multivariable models were constructed to study the effects of obestatin on heart, with other study variables taken into account as covariates. A $P$ value $<0.05$ was considered significant whether obtained from a one-tailed or two-tailed test of significance. Analyses involved SPSS v. 13.0 (SPSS Inc., Chicago, IL).

\section{Results}

\section{Baseline demographic features}

Genotyping was successful in 518 subjects. The TRIB3 Q84R polymorphism genotypes were in HardyWeinberg equilibrium (Table 2). Demographic characteristics of the study population are in Table 1. Serum obestatin was significantly decreased in MetS as compared with the control group. Demographic characteristics among different genotype subgroups are provided in Additional file 2: Tables S1 and S2.

\section{Effects of TRIB3 polymorphism on serum obestatin}

Among the control group, the obestatin concentrations of QQ84, QR84 and RR84 were 151.36 $\pm 11.75,102.33 \pm$ 14.45 and $95.50 \pm 17.39$, respectively; significant differences were observed between groups. Among the MetS group, participants possessing RR84 genotype had significantly lower levels of serum obestatin than those with QQ84 or QR84 genotypes (Table 3). Furthermore, MetS patients possessing RR84 genotype had even lower levels

\begin{tabular}{|c|c|c|}
\hline Variables & $\beta$ & $P$ \\
\hline \multicolumn{3}{|l|}{ carotid IMT } \\
\hline Age & 0.319 & 0.001 \\
\hline Obestatin & -0.294 & 0.003 \\
\hline
\end{tabular}

Abbreviations are as in Table 1. 
of serum obestatin than controls with RR84 genotype $(70.79 \pm 19.50$ vs $95.50 \pm 17.39, P=0.0001)$. The similar results in QQ84 genotypes.

\section{Association of decreased obestatin with carotid atherosclerosis in metabolic syndrome patients} What effect decreased obestatin exerts on carotid artery remains an open question. Correlation analysis showed that obestatin had a negative correlation with TC and LDL $(r=-0.202, P=0.018 ; r=-0.205, P=0.016$; respectively). Obestatin was negatively correlated with carotid IMT $(r=-0.256, P=0.011)$.

To get further insight into the association of serum obestatin with carotid IMT in subjects with MetS, partial analyses were performed. On partial analyses, obestatin was negatively correlated with carotid IMT $(r=-0.259$, $P=0.024$ ) after controlling for sex, age, SBP, DBP, waist circumference (WC), triglycerides, HDL-C, LDL-C, fasting blood glucose (FBG), insulin and smoking.

Furthermore, the factors with statistically significant associations with carotid IMT in the multivariable model were age $(\beta=0.319, P=0.001)$ and obestatin $(\beta=-0.294$, $P=0.003$, Table 4).

\section{Discussion}

To the best of our knowledge, this is the first study that aims to elucidate the interplay between MetS, TRIB3 polymorphism and obestatin. In the present study TRIB3 RR84 genotype with MetS saw further decreased obestatin. Furthermore, lowered obestatin might play an independent role in carotid atherosclerosis.

\section{TRIB3 polymorphism and obestatin}

TRIB3 is implicated in the regulation of insulin signal transduction [5] by binding to serine-threonine kinase $\mathrm{PKB} /$ Akt and blocking its activation. TRIB3, thus, is speculated to contribute to insulin resistance. Of note, a progressive reduction of insulin-induced $\operatorname{Ser}^{473}$ Akt phosphorylation was observed from untransfected control to Q84- and R84-expressing HepG2 cells with no changes of Akt protein expression [10]. However, obestatin enhanced glucose uptake in either the absence or presence of insulin, promoted GLUT4 translocation, and increased Akt phosphorylation, therefore reducing insulin resistance [3]. As mentioned above, since TRIB3 induces insulin resistance which would be reversed in part by obestatin, an important question has been whether the TRIB3 polymorphism would determine the level of serum obestatin.

Our results indicated that TRIB3 RR84 variant interacts significantly with MetS on the level of serum obestatin. As reported previously [4], obese subjects had significantly lower levels of obestatin. However, no genotype of the TRIB3 altered the level of serum obestatin among the control group. Further factorial analyses showed that TRIB3 RR84 variant will decrease the level of serum obestatin only in subjects with MetS.

In addition, it is important to acknowledge that only homozygous TRIB3 RR84 variant could decrease the level of serum obestatin in MetS individuals while heterozygous TRIB3 QR84 or homozygous TRIB3 QQ84 variants have no such, which suggested that here Q84 allele is dominant with $\mathrm{R} 84$ allele recessive.

\section{Obestatin and carotid artery in metabolic syndrome}

Most intriguing of all, our results showed that serum obestatin correlates inversely with IMT independent of the other potential affecting factors, which suggested that obestatin might have a bad effect on carotid atherosclerosis, otherwise obestatin may be a biomarker.

\section{Limitation}

Despite intriguing findings, the present results require confirmation by a prospective population study, since the MetS cohort was not all made up of newly diagnosed subjects. However, this study provides new insights into the potential associations of decreased obestatin with TRIB3 Q84R polymorphism, MetS and carotid atherosclerosis. In fact, without the foundation provided by the present study, the ensuing prospective population study could not be implemented.

\section{Conclusion}

In conclusion, our results confirmed that serum obestatin decreases with MetS, but further decreases due to TRIB3 RR84 genotype. Incremental serum obestatin might in part protect against carotid atherosclerosis.

\section{Additional files}

Additional file 1: Figure S1. Electrophoresis results on incubation with Mspl restriction enzyme.

Additional file 2: Table 1. Demographic characteristics of Control group by TRIB3 Q84R genotype. Table 2. Demographic characteristics of MetS group by TRIB3 Q84R genotype.

\section{Competing interests}

The authors declare that they have no competing interests.

\section{Authors' contributions}

ADC carried out the molecular genetic studies, participated in the sequence alignment and drafted the manuscript. NNG carried out the laboratory measurements, serum obestatin assay. XHZ participated in the Genotyping and Echocardiography. KZJ and ZJS participated in the design of the study and performed the statistical analysis. YLY and ADC conceived of the study, and participated in its design and coordination and helped to draft the manuscript. All authors read and approved the final manuscript.

Received: 13 August 2012 Accepted: 15 December 2012

Published: 17 December 2012 


\section{References}

1. Zhang JV, Ren PG, Avsian-Kretchmer O, Luo CW, Rauch R, Klein C, Hsueh AJ: Obestatin, a peptide encoded by the ghrelin gene, opposes ghrelin's effects on food intake. Science 2005, 310:996-999.

2. Gurriarán-Rodríguez U, Al-Massadi O, Roca-Rivada A, Crujeiras AB, Gallego R, Pardo M, Seoane LM, Pazos Y, Casanueva FF, Camiña JP: Obestatin as a regulator of adipocyte metabolism and adipogenesis. $J$ Cell Mol Med 2011, 15:1927-1940.

3. Granata R, Gallo D, Luque RM, Baragli A, Scarlatti F, Grande C, Gesmundo I, Córdoba-Chacón J, Bergandi L, Settanni F, Togliatto G, Volante M, Garetto S, Annunziata M, Chanclón B, Gargantini E, Rocchietto S, Matera L, Datta G, Morino M, Brizzi MF, Ong H, Camussi G, Castaño JP, Papotti M, Ghigo E: Obestatin regulates adipocyte function and protects against dietinduced insulin resistance and inflammation. FASEB J 2012, 26:3393-3411.

4. Nakahara T, Harada T, Yasuhara D, Shimada N, Amitani H, Sakoguchi T, Kamiji MM, Asakawa A, Inui A: Plasma obestatin concentrations are negatively correlated with body mass index, insulin resistance index, and plasma leptin concentrations in obesity and anorexia nervosa. Biol Psychiatry 2008, 64:252-255.

5. Du K, Herzig S, Kulkarni RN, Montminy M: TRB3: a tribbles homolog that inhibits Akt/PKB activation by insulin in liver. Science 2003, 300:1574-1577.

6. Koo SH, Satoh H, Herzig S, Lee CH, Hedrick S, Kulkarni R, Evans RM, Olefsky J, Montminy M: PGC-1 promotes insulin resistance in liver through PPAR-alpha-dependent induction of TRB-3. Nat Med 2004, 10:530-534.

7. Okamoto H, Latres E, Liu R, Thabet K, Murphy A, Valenzeula D, Yancopoulos GD, Stitt TN, Glass DJ, Sleeman MW: Genetic deletion of Trb3, the mammalian Drosophila tribbles homolog, displays normal hepatic insulin signaling and glucose homeostasis. Diabetes 2007, 56:1350-1356.

8. Gong HP, Wang ZH, Jiang H, Fang NN, Li JS, Shang YY, Zhang Y, Zhong M, Zhang W: TRIB3 functional Q84R polymorphism is a risk factor for metabolic syndrome and carotid atherosclerosis. Diabetes Care 2009, 32:1311-1313.

9. Matthews DR, Hosker JP, Rudenski AS, Naylor BA, Treacher DF, Turner RC Homeostasis model assessment: insulin resistance and beta-cell function from fasting plasma glucose and insulin concentrations in man Diabetologia 1985, 28:412-419.

10. Prudente S, Hribal ML, Flex E, Turchi F, Morini E, De Cosmo S, Bacci S, Tassi V, Cardellini M, Lauro R, Sesti G, Dallapiccola B, Trischitta V: The functional Q84R polymorphism of mammalian Tribbles homolog TRB3 is associated with insulin resistance and related cardiovascular risk in Caucasians from Italy. Diabetes 2005, 54:2807-2811.

doi:10.1186/1758-5996-4-52

Cite this article as: Cui et al:: Decreased serum obestatin consequent upon TRIB3 Q84R polymorphism exacerbates carotid atherosclerosis in subjects with metabolic syndrome. Diabetology \& Metabolic Syndrome 2012 4:52.

\section{Submit your next manuscript to BioMed Central and take full advantage of:}

- Convenient online submission

- Thorough peer review

- No space constraints or color figure charges

- Immediate publication on acceptance

- Inclusion in PubMed, CAS, Scopus and Google Scholar

- Research which is freely available for redistribution 